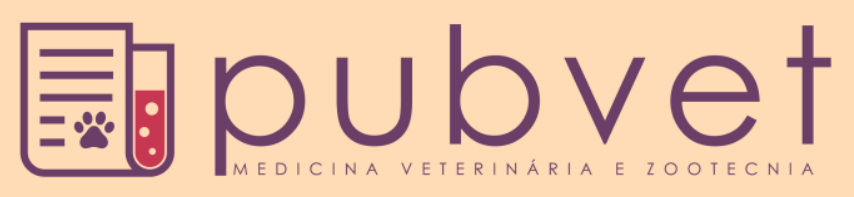

https://doi.org/10.22256/pubvet.v12n7a125.1-4

\title{
Efeito da declividade de bancada sobre a produção de alface
}

\author{
Orivaldo Maia de Araújo ${ }^{1}$, Marilia Constantino Mota $^{2}$, Antônio Florentino de Lima \\ Junior $^{30}$, Juracy Mendes Moreira ${ }^{4}$, Arinaldo Pereira da Silva ${ }^{50}$, Juliano Queiroz \\ Santana Rosa ${ }^{6 *} \bullet$
}

${ }^{1}$ Engenheiro Agronômico, E-mail: araujomaia2@hotmail.com

${ }^{2}$ Engenheiro Agronômico, E-mail: marilia.constantinoagro.16@outlook.com

${ }^{3}$ Prof. Faculdade Montes Belos. São Luiz de Montes Belos - GO. E-mail: agronomia@fmb.edu.br

${ }^{4}$ Prof. Faculdade Montes Belos. São Luiz de Montes Belos - GO. E-mail: juraci.moreira@fmb.edu.br

${ }^{5}$ Prof. Faculdade Montes Belos. São Luiz de Montes Belos - GO. E-mail: arinaldo.pereira@fmb.edu.br

${ }^{6}$ Prof. Faculdade Montes Belos. São Luiz de Montes Belos - GO. *Autor para correspondência. E-mail: julianoqsr@gmail.com

RESUMO. Nos últimos anos, além do plantio em canteiros a alface tem sido bastante cultivada em sistemas hidropônicos. Neste sistema as plantas são nutridas por uma solução nutritiva em circuito fechado, sendo assim, para que ocorra correta nutrição das plantas é necessária que o fluxo da solução ocorra de maneira adequada. Para tanto, é necessária uma certa declividade nas bancadas, que por sua vez, influencia a velocidade que a solução nutritiva passa pelo sistema radicular. Como existem poucas pesquisas sobre qual a declividade ideal para as bancadas, este trabalho teve o objetivo de avaliar o efeito da declividade da bancada sobre a produção da alface tipo americana (Cultivar Gloriosa). Avaliou-se quatro declividades de bancada: $3 \% ; 4 \% ; 5 \%$ e $6 \%$, em delineamento inteiramente casualizado com 6 repetições e 10 plantas por parcela. Na colheita foi avaliado massa fresca da parte aérea e massa das raízes. Foi realizada análise de Variância e teste de Scott-Knott para comparação das médias. Os resultados mostraram que os tratamentos com $4 \%$ e $5 \%$ apresentaram maior massa fresca da parte aérea e os demais não diferiram estatisticamente, para massa das raízes não houve diferença significativa entre os tratamentos.

Palavras chave: Cultivo hidropônico, Fluxo laminar, Solução nutritiva

\section{Effect of bench slope on lettuce production}

ABSTRACT. In recent years, besides planting in beds, lettuce has been widely cultivated in hydroponic systems. In this system as plants are nourished by a nutrient solution in a closed circuit, so that correct nutrition of the plants is necessary for the solution of the solution. Therefore, it is necessary a certain declination in the benches, in turn, influencing the speed of a nutrient solution by the root system. As there is little research on the ideal slope for benches, this work had the objective of evaluating the effect of bench slope on an American lettuce production (Cultivar Gloriosa). 4 stars: four percent; $4 \% ; 5 \%$ and 6\%, in a completely randomized design with 6 replicates and 10 plants per plot. Fresh shoot mass and root mass were evaluated. The analysis of Variance and Scott-Knott's test was performed to compare the means. The results showed that the treatments with $4 \%$ and $5 \%$ presented the highest fresh mass of the aerial part and the others did not differ statistically, for root mass there was no significant difference between the treatments.

Keywords: Hydroponic cultivation, Laminar flow, Nutrition solution 


\section{Efecto de la pendiente de bancada sobre la producción de lechuga}

RESUMEN. En los últimos años, además de la plantación en canteros la lechuga ha sido bastante cultivada en sistemas hidropónicos. En este sistema las plantas son nutridas por una solución nutritiva en circuito cerrado, siendo así, para que ocurra correcta nutrición de las plantas es necesario que el flujo de la solución suceda de manera adecuada. Para ello, es necesaria una cierta declividad en las bancadas, que a su vez influye en la velocidad que la solución nutritiva pasa por el sistema radicular. Como hay pocas investigaciones sobre cuál es la declividad ideal para las bancadas, este trabajo objetivó evaluar el efecto de la declividad de la bancada sobre la producción de la lechuga tipo americana (Cultivar Gloriosa). Se evaluaron cuatro declividades de bancada: $3 \% ; 4 \% ; 5 \%$ y $6 \%$, en delineamiento completamente casualizado con 6 repeticiones y 10 plantas por parcela. En la cosecha se evaluó la masa fresca de la parte aérea y la masa de las raíces. Se realizó un análisis de Varianza y prueba de Scott-Knott para la comparación de los promedios. Los resultados mostraron que los tratamientos con $4 \%$ y $5 \%$ presentaron mayor masa fresca de la parte aérea y los demás no diferían estadísticamente, para masa de las raíces no hubo diferencia significativa entre los tratamientos.

Palabras clave: Cultivo hidropónico, Flujo laminar, Solución nutritiva

\section{Introdução}

Segundo Rodrigues (1997) produção hidropônica é a produção fora do solo. Neste contexto englobam a produção em recipientes com substratos sólidos como exemplo a fibra de coco, ou a produção em circuitos fechados com circulação de soluções nutritivas (NFT). O NFT (Nutrient film technique) consiste em uma técnica que permite o cultivo em uma lâmina de água onde são acrescentados todos os nutrientes necessários ao desenvolvimento da planta em bancadas, geralmente compostas por canos de PVC com suporte para diversos cultivares.

De acordo com Beninni et al. (2003), A declividade da bancada é um aspecto importante na produção hidropônica, que através de trabalhos verificou-se que ao longo dos últimos anos, podese constatar uma evolução na recomendação quanto às declividades adotadas para o sistema NFT, composto basicamente de um tanque de solução nutritiva, de um sistema de bombeamento, dos canais de cultivo e de um sistema de retorno ao tanque. A solução nutritiva é bombeada aos canais e escoa por gravidade formando uma fina lâmina de solução que irriga as raízes. De acordo com Furlani et al. (1999) na década de 90 a recomendação da declividade a ser adotada era entre 2 e $4 \%$, com comprimento máximo de bancada de $12 \mathrm{~m}$., assim a bancada iniciava com $0.50 \mathrm{~m}$ e finalizava com $0.98 \mathrm{~m}$ (diferença de $0.48 \mathrm{~m}$, considerando-se $4 \%$ de declividade, com a implantação do sistema em um terreno plano). Atualmente recomenda-se a instalação da bancada com a declividade variando entre 8 a $10 \%$ e comprimento máximo de $12 \mathrm{~m}$, gerando assim um problema na altura da bancada na extremidade na qual é injetada a solução nutritiva devido a altura considerando-se $10 \%$ de declividade. Diante disto, este trabalho tem o objetivo de avaliar o efeito da declividade da bancada sobre a produção da alface tipo americana (Cultivar Gloriosa).

\section{Materiais e Métodos}

O experimento foi conduzido na cidade de São Luís de Montes Belos-GO, com latitude de $16^{\circ} 30^{\prime} 42.67$ 'S, longitude de 50'30'15.78"0 e altitude média de 576 metros. Para a realização do experimento foram utilizadas sementes do cultivar gloriosa.

O transplante das mudas foi realizado em ambiente protegido com estrutura metálica do tipo arco, com área total de $10 \mathrm{~m} \times 6 \mathrm{~m}$ e, uma área de $60 \mathrm{~m}^{2}$, com $2,50 \mathrm{~m}$ de altura, coberta com filme de polietileno transparente de baixa densidade com 150 micras de espessura. A estrutura possui lateral feita de sombrite nylon com passagem de $80 \%$ de luz. Foram utilizadas 4 bancadas, com $9 \mathrm{~m}$ de comprimento por $50 \mathrm{~cm}$ de largura cada, à altura de $1 \mathrm{~m}$ do nível do solo na parte mais alta, com $3 \% ; 4 \% ; 5 \%$ e $6 \%$ de declividade. Cada bancada possuía 2 canos de PVC com $75 \mathrm{~mm}$ de espessura cada, com capacidade de suporte para 36 plantas. Todas as bancadas foram alimentadas com solução nutritiva vindas de um reservatório de 500 litros, onde cada solução nutritiva alimentava 2 canais de cultivo para cada bancada, a solução foi mantida inalterada ao longo de todo o ciclo da cultura. 
A semeadura das mudas foi realizada em espuma fenólica, com células de $2 \mathrm{~cm} \times 2 \mathrm{~cm} \times 2$ $\mathrm{cm}$. Foram depositadas uma semente nua por célula. Com 11 dias após a semeadura (DAS), depois de atingirem de 4 a 5 folhas definitivas, as mudas foram transplantadas para o berçário onde ficaram por 15 dias, sendo irrigadas de 15/15 minutos na parte de manhã e depois das 12:00 continuamente até às 17:00, voltando após as 17 horas a frequência de irrigação a cada $15 \mathrm{~min}$, tendo a vasão no fluxo laminar de meio litro de solução por minuto. Durante o experimento as plantas receberam solução nutritiva (formulação em anexo), com condutividade elétrica de 2.0 $\mathrm{mS} . \mathrm{cm}^{-1}$ e $\mathrm{pH}$ em torno de 6,0 .

Após 45 dias de cultivo foram colhidas para avaliação 10 plantas aleatórias por canal. O delineamento utilizado para avaliar o efeito das soluções no desenvolvimento das plantas foi inteiramente casualizado com 6 repetições, sendo avaliados em balança eletrônica peso fresco da matéria aérea (folha) e raiz das plantas. Foi realizada análise de variância, teste de Scott-Knott para comparação de médias e análise de regressão utilizando o software estatístico $\mathrm{R} \quad(\underline{\mathrm{R}}$ Development Core Team, 2014).

\section{Resultados e discussão}

Observando a Tabela 1 se percebe que não houve diferença significativa para produção de massa do sistema radicular. Com relação à massa fresca da parte aérea houve diferença significativa sendo que a declividade 4 e $5 \%$ foram superiores e não diferirão entre si. Isto ocorreu porque provavelmente, quando a declividade é pequena a solução aquece provocando a redução de oxigenação. Por sua vez, quando a declividade é muito alta a solução há pouco contato da raiz com a solução.

Tabela 1. Massa fresca da parte aérea e do sistema radicular da alface cv. Gloriosa.

\begin{tabular}{lcc}
\hline Declividade & $\begin{array}{c}\text { Massa Aérea } \\
\text { Parcela }\end{array}$ & $\begin{array}{c}\text { Massa Da Raiz } \\
\text { Parcela }\end{array}$ \\
\hline $3 \%$ & $1331,33 \mathrm{~b}$ & $448,16 \mathrm{a}$ \\
$4 \%$ & $1528,16 \mathrm{a}$ & $471,16 \mathrm{a}$ \\
$5 \%$ & $1405,50 \mathrm{a}$ & $395,66 \mathrm{a}$ \\
$6 \%$ & $1259,50 \mathrm{~b}$ & $444,83 \mathrm{a}$ \\
\hline $\mathrm{CV}$ & $10,21 \%$ & $12,81 \%$ \\
\hline *Médias seguidas pela mesma letra não diferiram \\
significativamente pelo teste de Scott-knott a 5\%.
\end{tabular}

Para evitar problemas na oxigenação e consequentes perdas do sistema radicular por apodrecimento devido a elevações de temperatura, um sistema eficiente não deve apresentar temperaturas acima de $30^{\circ} \mathrm{C}$ (Villela Júnior et al., $\underline{2004})$

Para massa verde além da análise qualitativa foi realizada análise de regressão, sendo a regressão quadrática significativa (Figura 1).

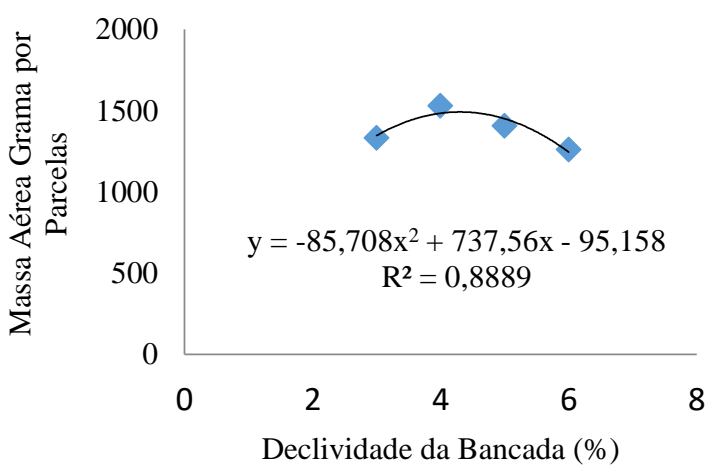

Figura 1. Curva de produção da massa aérea da Alface cv. Gloriosa em função da declividade da bancada.

A partir da equação foi possível calcular a declividade ótima que foi de $4,3 \%$, resultado este que corrobora com as recomendações mais clássicas de NFT como as de Furlani et al. (1999).

\section{Conclusão}

Através do experimento realizado em sistema hidropônico com a declividade de bancada entre $3 \%$ e $6 \%$, conclui-se que o melhor resultado obtido para o desenvolvimento da alface tipo americano (cv. Gloriosa) foi entre $4 \%$ e $5 \%$ em que se observou um desempenho satisfatório entre a evolução das partes aérea e raiz. Calculou-se ainda que a declividade de bancada a $4.3 \%$ é a declividade de máxima produção de massa fresca da parte aérea da alface tipo americana (cv. Gloriosa).

\section{Referências bibliográficas}

Beninni, E. R. Y., Takahashi, H. W. \& Neves, C. S. V. J. 2003. Manejo do cálcio em alface de cultivo hidropônico. Horticultura Brasileira, 21(4), 605-610.

Furlani, P. R., Silveira, L. C. P.; Bolonhezi, D. \& Faquim, V. 1999. Cultivo hidropônico de plantas (52 p.). Instituto Agronômico, Campinas, São Paulo, BR. 
R Development Core Team. 2014. R Foundation for Statistical Computing, versão 2.13.1. Vienna, AT.

Rodrigues, A. B., Martins, M. I. E. G. \& Araújo, J. C. C. 1997. Avaliação econômica da produção de alface em estufa. Informações econômicas, 27(1), 27-33.

Villela Júnior, L. V. E, Araújo, J. A. C. \& Factor, T. L. 2004. Análise do resfriamento da solução nutritiva para cultivo hidropônico do morangueiro. Engenharia Agrícola, 24(2), 338-346.

Recebido:18 Abr. 2018

Aprovado: 4 Mai. 2018

Publicado: 30 Jun. 2018

Licenciamento: Este artigo é publicado na modalidade Acesso Aberto sob a

licença Creative Commons Atribuição 4.0 (CC-BY 4.0), a qual permite uso

irrestrito, distribuição, reprodução em qualquer meio, desde que o autor e a

fonte sejam devidamente creditados. 